\title{
Amadeus
}

International Multidisciplinary Journal ISSN 2525-8281

\section{Neurorehabilitation with Padovan Method in a Newborn with Treacher Collins Syndrome: A Case Report}

\section{Erikson de Luna Delmondes ${ }^{1}$; Lucas Tavares Cruz de Albuquerque ${ }^{2}$; Lilianny Medeiros Pereira ${ }^{3}$}

\begin{abstract}
Treacher Collins Syndrome (TCS) is an autosomal dominant disorder that leads to congenital craniofacial malformation and may then be assisted by the Padovan Method ${ }^{\circledR}$ for neurological rehabilitation. The aim of this article is to report the functional improvements obtained by a patient with TCS who underwent the Padovan Method ${ }^{\circledR}$. The child was born on november 26th of 2014, cesarean delivery, 37 weeks, Apgar 9/10, weighted $3625 \mathrm{~g}, \mathrm{PC}=35 \mathrm{~cm}, \mathrm{C}=49 \mathrm{CM}$, presenting mild respiratory discomfort, absence of suction and the presence of syndromic facies, which is characteristic of TCS with retrognathism, oblique palpebral cleft downward divergent strabismus on left, pointed ears with cleft lobes, narrow auditory canal, malar hypoplasia and narrow palate. Padovan therapy was initiated at the 6th day of life, from orofacial, vestibular, ocular and motor exercises that seek to recapitulate the neuroevolutionary phases of human development with the purpose of propitiating a motor and neurological maturation of the central nervous system (CNS) and the correction of its possible failures. The child presented suction on the second day of therapy and on the fifth day was discharged from the hospital with good suction to the breast. The patient was followed up on an outpatient office and was given physiotherapy and speech therapy. The patient no longer received the Padovan Method $\AA$ because at that time it was not available outside the hospital. Upon returning to childcare at age of 3 , a good motor coordination performance was noticed, also speaking few loose words, but with good interaction and understanding. Therefore, due to the lack of standard behavior in neonatal neurological rehabilitation, considering the concepts of neuroplasticity andknowing the importance of early intervention, the Padovan Method ${ }^{\circledR}$ is shown as an alternative in the CNS reorganization in patients with TCS.
\end{abstract}

Keywords: Padovan Method. Treacher Collins Syndrome. Neuroplasticity. Neurorehabilitation.

\footnotetext{
${ }^{1}$ Medical student at the Estácio Medical School of Juazeiro do Norte (FMJ), Ceará, Brazil. Contact: eriksonluna11@gmail.com

${ }^{2}$ Medical student at the Estácio Medical School of Juazeiro do Norte (FMJ), Ceará, Brazil. Contact: lucastavares47@gmail.com

${ }^{3}$ Pediatrician, specialist in Neonatology by the Federal University of Rio Grande do Norte (UFRN). Teacher at Estácio Medical School of Juazeiro do Norte (FMJ). Contact: liliannypediatra@ hotmail.com.
} 


\section{Introduction}

Treacher Collins Syndrome (TCS) or mandibular dysostosis is an autosomal dominant disorder involving the congenital malformation of the first and second pharyngeal arches and affects 1 in 50,000 live births (Dixon; Trainor; Dixon, 2005; Polanski; Plawiak: Ribas, 2015). It is caused by mutations in the TCOF1, POLR1C and POLR1D genes and it is estimated that $60 \%$ of the cases are the results of new mutations and $40 \%$ inherited mutations (Cassab et. al., 2012).

This syndrome is characterized by craniofacial malformations suchs as the antimongoloid inclination of the eyelid fissures, lower eyelids coloboma, malar hypoplasia, micrognathia, cleft palate and absence of malformation of the external ear and conductive channels, which leads to conductive deafness (Pollo et. al, 2014). Anomalies in TCS are usually symmetrical and bilateral (Cassab et. al., 2012). Patients with TCS usually suffer from airway obstruction, obstructive sleep apnea and respiratory failure (Ligh et. al., 2017). However, speech disorders, chewing, swallowing and corneal exposure should be evaluated (Yoshida; Tonello; Alonso, 2012). The care of children with this disorder is multidisciplinary, requiring a team formed by an otorhinolaryngologist, ophthalmologist, neurologist, pediatrician, psychologist, dentist, social worker, occupational therapist and physiotherapist (Rodrigues et al., 2015). The rehabilitation of the patients can be done from a clinical or surgical process, depending on the extensiveness of the deformities (Lewillie, 2017).

TCS treatment should be started from the prenatal period, where the family will be guided about the characteristics of the syndrome and the care needed over the course of life (Silva et. al., 2008). Neonatal rehabilitation is mainly aimed at correcting the main problems that are affecting the newborn at that moment, to improve the respiratory pattern and establish coordination of suction-breathing-deglutition, avoiding bronchoaspiration and delays in the development of children, but not there is a standard rehabilitation protocol for this period (Basu, 2014; Rodrigueset al., 2015). However, since 2008, the Padovan Method® of neurofunctional rehabilitation has been used as standard therapy in the neonatal intensive care unit of the São Lucas Municipal Hospital, in Juazeiro do Norte, Ceará, for the rehabilitation of newborns with any neurological impairment to reduce the hospitalization and improve the patients' quality of life (Pereira et al., 2015; Pereira; Vileicar; Uchôa, 2018). 
The Padovan Method ${ }^{\circledR}$ also known as the Neurofunctional Reorganization Method was developed in the early 1970s by speech therapist Beatriz Padovan based on the ideas of Rudolf Steiner and Temple Fay. According to Steiner's studies, the processes of walking, speaking and thinking are interdependent, that is, there is a correlation between the motor and cognitive processes, in which simple skills were first developed rather than more complex, following a maturation sequence of the Central Nervous System. Fay's teachings were about the concept of "Neurological Organization", in which, due to the plasticity of the nervous system, a sequence of neuroevolutionary movements was performed in the patients passively until they had the autonomy to perform them actively (Lasagno, 2014; Bender, 2017). From this, this method uses body exercises that are based on human neuroevolutionary movements, specific activities for all oral vegetative reflex functions (chewing, swallowing, sucking and breathing) and exercises for the eyes and hands (Lasagno, 2014).

This study aims to report the good results of the Padovan Method® in a patient with Treacher Collins Syndrome as an alternative to the treatment of neurorehabilitation with the studies in early stimulation in the neonatal period.

\section{Case}

The child was born on november 26th of 2014, cesarean delivery, 37 weeks, Apgar 9/10, weighted $3625 \mathrm{~g}, \mathrm{CP}=35 \mathrm{~cm}, \mathrm{~L}=49 \mathrm{CM}$, presenting mild respiratory discomfort, absence of suction and the presence of syndromic facies, which is characteristic of TCS with retrognathism, oblique palpebral cleft downward divergent strabismus on left, pointed ears with cleft lobes, narrow auditory canal, malar hypoplasia and narrow palate.He did not have infection, nor did he need ventilatory support, but because he did not present suction, Padovan ${ }^{\circledR}$ Therapy was started at 6 days of age. Proposed exercises were performed for the neonatal period consisting of vestibular stimulation, motor exercises of legs, arms, hands and head that integrate the muscular chains, manual diaphragmatic exercises and breathing exercises with whistles in the nose and mouth, which stimulate, besides the olfactory nerve, the musculature of the rhinopharynx and larynx. Sequentially exercises with flashlight for visual and photomotor stimulation, also exercises with face and intraoral vibrator, exercises with tongue elastic for suction and swallowing, passive stimulation of suction with gloved 
finger, all these orofacial exercises stimulating the cranial nerves that are responsible for the motor and sensory function of the head and neck muscles.

On the second day of therapy the baby presented suction soon after therapy, but not at other times of the day. The therapy continued daily and on the fifth day the baby was discharged from the hospital with good suction to the breast.

The patient was followed up on an outpatient office and was given physiotherapy and speech therapy. The patient no longer received the Padovan Method® because at that time it was not available outside the hospital. By the time the baby was 3 months old he fixed and watched the objects, rolled at 4 months, normal otoacoustic emissions, exclusively breastfed up to 5 months, with good weight gain, sat at 7 months, did not crawl until 10 months, walked 1 year and 6 months. Between 1 year and 3 months to 3 years, the baby did not have pediatric follow-up, due to crises of sinusitis and tonsillitis the mother took the child to pediatric emergency and otorhinolaryngologist. Upon returning to childcare at age of 3, a good motor coordination performance was noticed, also speaking few loose words, but with good interaction and understanding.

\section{Discussion}

There is no standard method for the therapeutic approach of patients with TCS, mainly because it affects a variety of structures of the human body (Silva et al, 2008). The syndrome treatment should be directed primarily to disorders regarding breath, chewing, speech, swallowing and corneal exposure. From this, there is an extensive variability of surgical treatments for corrections of deformities, where the future effects of this early therapy must be considered, due to craniofacial development (Yoshida; Tonello; Alonso, 2012). The conduct may also be clinical and functional, to improve the motor function and neuropsychomotor development of the patient (Rodrigues et al, 2015).

Patients with TCS have structural defects that can affect normal craniofacial development with severe neuropsychomotor repercussion when diagnosis and rehabilitation are late and the Padovan Method ${ }^{\circledR}$ has been shown to be effective in the quality of life of patients who are born with CNS-compromising abnormalities, by the early stimulation of the activities that involve it. (Pereira, 2015; Silva et al., 2008). 
In the case reported above, the patient had typical TCS facies and presented respiratory and suction disturbances as the most emergent ones to be addressed. There was an absence of suction and a mild respiratory discomfort, not requiring the use of mechanical ventilation, but that would impair its oral feeding and delay its discharge from hospital, besides the risk of complications such as bronchoaspiration. As it has been used in the service since 2008, the Padovan Method ${ }^{\circledR}$ has been started for the patient early, with exercises that stimulate oral, vestibular, ocular, motor and auditory reflexes and serve as a positive input to neurogenesis and synaptogenesis (Frazão; Pereira; Silva. 2012; Pereira; Vileicar; Uchôa, 2018), obtaining good suction within the five therapies, which can be explained by the fantastic ability of neuroplasticity in the early stages of development, such as in the neonatal period (Pereira et al., 2015).

Neuroplasticity is the ability of the nervous system to modify its structure and function as a result of patterns of experience, and it is in this theory that the method is also based on the creation of an environment rich in stimuli that provide the necessary excitation for the modification of the neural circuits and the consequent acquisition of the various cerebral capacities (Frazão; Pereira; Silva, 2012; Pereira,2015). Up to 2 years of age, a person has greater potential for neuroplasticity, the so-called critical period, which is essential for the normal development of the nervous system, and the interval at which the Padovan Method ${ }^{\circledR}$ is expected to show the best results (Pereira et al., 2015).

The exercises have the purpose of promoting the neurofunctional reorganization defended by the method, from the recapitulation of the neuroevolutionary phases of human development for the Walk-Talk-Think (Lasagno, 2014).

Neurological organization is a natural process that leads to a maturation of the CNS, making the individual become able to fulfill their genetic potential (Simões; Arthidoro, 2011). The Padovan Method® seeks the reorganization of this system trying to propitiate the development of motor and neurological maturation and correction of possible failures, being thus, suitable for all ages, as curative, preventive or maintenance of the nervous system. (Pereira, 2015). Padovan exercises should respect the development phase in which the patient is, always following the sequence of movements of the natural neuroevolution, from rhythmic, regular and repetitive exercises, which can favor the rearrangement of new neural connections and consequently the neurofunctional reorganization (Simões; Arthidoro, 2011). 
This work of neonatal neuro-rehabilitation with the Padovan Method® has been used routinely in our service in Ceará's countryside for 10 years, with excellent results, being effective mainly in the establishment of coordinated suction, allowing the patient to be discharged from the hospital with good suction to the breast, in this series published in 2015, no patient required gastrostomy or tracheostomy (Pereira, 2015).

\section{Conclusion}

Given the lack of standard procedure in neonatal neurological rehabilitation, considering the concepts of neuroplasticity, knowing the importance of early intervention and as exposed how the Padovan Method ${ }^{\circledR}$ works in the reorganization of the Central Nervous System, we hope to contribute with the reports of our clinical experience to arouse the interest of scholars in the area of neuro-rehabilitation in spreading scientific studies about the method and, with this, benefit more patients.

\section{References}

Basu, A. P. (2014). Early intervention after perinatal stroke: opportunities and challenges. Developmental Medicine \& Child Neurology, (56)6, 516-521.

Bender, N. A (2017). Myofunktionelle Therapie in der Padovan-Methode ${ }^{\circledR}$ Neurofunktionelle Reorganisation. Sprachtherapie Aktuell: Forschung - Wissen - Transfer, 1-18.

Cassab, T. V. et al. (2012). Alterações de fala na síndrome de Treacher Collins. Rev Bras Cir Craniomaxilofac, (2)15, 69-73.

Dixon, I.; Trainer, P.; Dixon, M. P. (2007). Treacher Collins syndrome. Orthod Craniofacial Res, (10), 88-95.

Frazão, A. P.; Pereira, L. M.; Silva, M. G. N. (2012). Estimulação Neurofuncional dos cincos sentidos com o Método Padovan. Trabalho de conclusão de curso. Faculdade de Medicina Estácio de Juazeiro do Norte, Juazeiro do Norte. CE, Brasil.

Lasagno, A, G. S. (2014). O método Padovan TM de reorganização neurofuncional . $9^{\circ}$ E ncontro, $11^{o}$ Congresso brasileiro, $3^{a}$ Convenção Brasil Lainoamérica de psicoterapias corporais, Curitiba, PR, Brasil. 
Lewyllie, A. et al. (2017). Three-dimensional imaging of soft and hard facial tissues in patients with craniofacial syndromes: a systematic review of methodological quality. Dentomaxillofacial Radiology, 54-82.

Ligh, C. A. et al. (2017). A Morphological Classification Scheme for the Mandibular Hypoplasia in Treacher Collins Syndrome. Journal Of Craniofacial Surgery, (28)3, 683-687.

Pereira, L. M. (2015). Padovan Method As Early Stimulation In Neonatal Intensive Care Unit. International Archives Of Medicine, 1-14.

Pereira, L. M. et al. (2015). Padovan Method Of Neurofunctional Reorganization As A Way For Neurological Recovery In Newborns. International Archives Of Medicine , 1-16.

Pereira, L. M.; Vileicar, D. C.; Uchôa, M. M. A. (2018). Neurorreabilitação com o método Padovan em recém-nascidos com síndrome alcoólica fetal: relato de 2 casos. J Health Biol Sci. (6)2, 214-216.

Polanski, J. F.; Plawiak, A. C.; Ribas, A. (2015). Angela. Reabilitação auditiva na Síndrome de Treacher Collins por meio de prótese auditiva ancorada no osso. Rev Paul Pediatr , (4)33, 483487.

Pollo, J. M.M. et al. (2014). Síndrome de Treacher-Collins. Presentación de un caso. Rev MédElectrón , (36) 2.

Rodrigues, B. G. da S. et al. (2015). . Evolution of a child with Treacher Collins syndrome undergoing physiotherapeutic treatment. Fisioterapia em Movimento , (28)3, 525-233.

Silva, D. L. da et al. (2008). Síndrome de Treacher Collins: Revisão de Literatura. Arq. Int. Otorrinolaringol. / Intl. Arch. Otorhinolaryngol , (12)1, 116-121.

Simões, N. S. S.; Arthidoro, P. Z. (2011). Proposta de Aplicação do Método padovan de Reorganização Neurofuncional na UTI Neonatal: enfoque fonoaudiólogo. Dissertação (Terapia Intensiva). Instituto Brasileiro de Terapia Intensiva, Rio de Janeiro, RJ, Brasil.

Yoshida, M.; Tonello, C.; Alonso, N. (2012). Síndrome de Treacher Collins: desafio na otimização do tratamento cirúrgico. Rev Bras Cir Craniomaxilofac , (2)15, 64-68.

\section{How to cite this article (APA format):}

Delmondes, Erikson de Luna; Albuquerque, Lucas Tavares Cruz de; Pereira, Lilianny Medeiros. (2018). Neurorehabilitation with Padovan Method in a Newborn with Treacher Collins Syndrome: A Case Report. Am. In. Mult. J., Oct. (5) 3, 01-07.

Received: 07/30/2018.

Accepted: 08/10/2018. 